\title{
Collaboration on risk management: the governance of a non- potable water reuse scheme in London
}

\author{
D. Goodwin ${ }^{1}$, M. Raffin ${ }^{2}$, P. Jeffrey ${ }^{1}$, H. M. Smith ${ }^{1}$ \\ ${ }^{1}$ Cranfield Water Science Institute, Cranfield University, Bedfordshire, UK, MK43 OAL \\ ${ }^{2}$ Thames Water Utilities Ltd, Dace Road, Bow, London, UK, E3 2NW \\ Corresponding author, h.m.smith@cranfield.ac.uk
}

\begin{abstract}
Ageing water infrastructure and population growth, issues that are characteristic of megacities, are likely to exacerbate water supply deficits in London. To address this threat, wastewater reclamation and non-potable reuse can potentially close the supply-demand gap without impacting on environmental water bodies. There is a need to understand the types of challenges that diverse stakeholders face in relation to the governance of NPR schemes, and how those challenges might be addressed in a megacity context. A case study is used to explore these challenges for an operational sewer mining scheme in London, where reclaimed non-potable water is used for irrigation and toilet flushing at the site of the London 2012 Olympic Park. Through qualitative analysis of interview and document data, the results highlight that collaboration and learning opportunities are perceived as necessary to improve scheme governance. The findings indicate that formal and informal engagement activities centred on risk management can support the development of common understandings, build important inter-stakeholder relationships and help maintain trust. Nonpotable reuse can contribute to the resilience of megacities through infrastructure diversification, but its feasibility will depend on the willingness of stakeholders to participate and continually negotiate new risk management practices.
\end{abstract}

\section{Keywords}

Non-potable reuse, water reuse, risk, governance, collaboration 


\section{Introduction}

Megacities magnify and concentrate risks related to water infrastructure failure, water stress and water quality (IRGC, 2010; Li et al., 2015). These qualities have an acknowledged impact on water supply and this has helped to elevate the viability of water reuse as an urban water management option (Furlong et al., 2016; Van Leeuwen and Sjerps, 2015). Examples of water reuse scheme contributions in megacities include aquifer recharge in Mexico City (Sosa-Rodriguez, 2011) and onsite reclamation and reuse in individual buildings in Tokyo (Kimura et al., 2013). Approaches to water reuse encompass larger-scale schemes that use highly treated effluent to augment public drinking water supplies (e.g. Orange County, California or Big Spring, Texas), as well as smaller-scale schemes providing non-potable water for specified uses (e.g. urban irrigation, toilet flushing, or street cleaning). Such non-potable reuse (NPR) water supply options can be economical (depending on the characteristics of the design and the economic assessment of benefits - Bieker et al., 2010) and adaptable to existing water infrastructure constraints (e.g. where there are potable water network or sewer capacity issues). This can make them particularly suited to high growth areas of megacities (Tjandraatmadja et al., 2005).

NPR schemes are associated with a complex set of risks, including health risks from exposure to nonpotable water, as well as broader risks related to environmental impacts, public perceptions, and financial viability of schemes (Furlong et al., 2017). Financial risks are of particular relevance and can arise from a mismatch between supply and demand (Turner et al., 2016), difficulty obtaining capital funding (Furlong et al., 2017) and delays in project delivery (West et al., 2016). Other recognised risk factors for NPR schemes include meeting customer expectations (West et al., 2016) and political aspects of water resource management (Furlong et al., 2016). Risk management is therefore essential for providing safe and viable non-potable water supplies (Hochstrat et al., 2008; Toze, 2006). However, it is also acknowledged that contemporary risk management processes for water 
supplies (e.g. the Water Safety Plan) may not adequately capture broader risks associated with different water reuse schemes (Goodwin et al., 2015; Huxedurp et al., 2014) nor an appropriate range of stakeholder perspectives (Campbell and Scott, 2011). The governance of NPR schemes can be challenged by efforts to minimise risks to public health and the environment, particularly where adherence to a wide range of (often fragmented or overlapping) guidelines, regulations and policies is required (Hanjra et al., 2012). Efforts to address these challenges can be further hampered if the many stakeholders involved have an inadequate understanding of their different roles and responsibilities, which may lead to conflicts if (for example) contractual arrangements have not worked (Turner et al., 2016). While previous studies have examined governance approaches for NPR (e.g. Dillon et al., 2010; Domènech and Saurí, 2010; Hanjra et al., 2012), there remains a general need for evidence to inform the development of clearer and more effective processes for managing such schemes.

Megacities present a particularly challenging context for the governance of NPR schemes, due to the scale of water supply issues and the number and diversity of potential stakeholders (Varis et al., 2006). These issues can lead to fragmentation of technological and management solutions (Li et al., 2015) and of stakeholder responsibilities and decision making (Varis et al., 2006). Such fragmentation can exacerbate existing water management problems (Li et al., 2015) whilst also increasing the potential for misunderstandings and conflict between stakeholders (Brown, 2008). Many solutions to these challenges centre on developing more inclusive stakeholder engagement processes (Lebel et al., 2015). However, there is a need for a better understanding of how the inclusion of multiple stakeholders can improve the governance of NPR schemes (Ferguson et al., 2013), with particular reference to regulatory oversight (Hanjra et al., 2012) and risk management activities (Dunn et al., 2015). 
The incorporation of reuse schemes in long-term strategic plans is often considered as part of an integrated urban water management approach (IUWM), which advocates the consideration of multiple water sources and services, as well as the inclusion of a wide range of stakeholders, in order to achieve the best community outcomes (Furlong et al., 2016). However, the recognised lack of critically reported practical experience describing how NPR might be incorporated into such strategic water management approaches (Ferguson et al., 2013) highlights the benefits of learning from case specific evaluations (Moglia et al., 2011). Specifically, this study contributes to the aforementioned gaps through a case study of a community-scale water recycling scheme in the urban growth area of East London. The queries guiding this study are: (i) what are the main challenges that stakeholders see in relation to managing the risks (particularly health risks) associated with the NPR scheme; (ii) how do they think those challenges might be overcome in order to promote more effective NPR scheme governance; and (iii) how might case specific learnings inform practical aspects of future NPR schemes in London and other megacities? The following sections outline the research methods (including a description of the case study) and present the results. The discussion then considers the practical implications of the research findings, particularly in light of current understandings around the inclusion of stakeholders in NPR scheme governance, with reference to the megacity context.

\section{Methods}

This study employed a single case study approach (Yin, 2012) and collected and analysed data from semi-structured interviews and documents. Similar approaches have been used by a number of related studies to draw practical insights into aspects of water reuse (e.g. Marks and Zadoroznyj, 2005; Marks, 2006), integrated urban water management (e.g. Ferguson et al., 2013), water safety planning (e.g. Perrier et al., 2014) and risk governance (e.g. Dunn et al., 2015; Mauelshagen et al., 2014). This section will first describe the case study and then describe the methods of data collection and analysis. 


\subsection{Case study description}

The selected case was the Old Ford Water Recycling Plant (OFWRP) which constitutes the largest community-scale NPR scheme in the United Kingdom. The scheme was implemented for the London 2012 Olympic and Paralympic Games and formed part of the event's sustainable water strategy (Knight et al., 2012). The scheme involves abstracting wastewater from a combined sewer (the Northern Outfall Sewer), treating it with a membrane bioreactor followed by granular activated carbon and disinfection with sodium hypochlorite, and distributing it through dual pipe reticulation to customers located at the nearby Queen Elizabeth Olympic Park (QEOP) (Figure 1). The average flow in the combined sewer is $116,000 \mathrm{~m}^{3} /$ day, whilst the OFWRP is designed to provide $574 \mathrm{~m}^{3} /$ day of non-potable water (Hills and James, 2014). The non-potable water supply is used both directly and indirectly (through topping up rainwater and stormwater harvesting systems) for irrigation and toilet flushing. A unique regulatory position and unique water quality standards were required for the scheme as it was the first of its kind in the country. A Water Reuse Safety Plan (WRSP) approach was developed for risk assessment and management (based on the format used in drinking water regulation).

\section{Figure 1. The physical catchment to tap boundary of the scheme}

The stakeholders involved in the OFWRP scheme have a wide range of roles and responsibilities. Thames Water Ltd is responsible for the OFWRP, the combined sewer and the dual pipe distribution network. In terms of the Olympic Park planning and management, the Olympic Delivery Authority (ODA) was the public body responsible for delivering the London 2012 Olympic and Paralympic Games and implemented the scheme in partnership with Thames Water (Knight et al., 2012). Following the Olympics, the ODA handed responsibilities for planning and development in the Park to the London Legacy Development Corporation (LLDC). The LLDC are also customers of the OFWRP, 
overseeing the use of the non-potable water in a number of venues and across the parklands for irrigation. Other venues and areas of the park are the responsibility of the Lee Valley Regional Park Authority and, adjacent the park, East Village is indirectly connected to the non-potable water network. Finally, the venues and parkland within the Olympic Park play host to a range of local and international events and are frequented by both the general public as well as members of sporting and community organisations.

The Old Ford scheme also helps address the broader water supply challenge for London, wherein current water balance models predict an emerging public potable water supply deficit of up to 414 mega-litres per day by 2040 (Thames Water, 2014). The population of Greater London (the third largest of the three UN defined European megacities after Moscow and Paris) is predicted to grow to 11.5 million by 2030 (United Nations, 2015) - particularly in over forty designated development opportunity and intensification areas (Greater London Authority, 2015a) This growth is projected to be highest in the east of the city, with an extra 600,000 people living in areas including and surrounding the case study location by 2040 (Greater London Authority, 2015b). Planned development includes residential housing growth along with new office space, retail space, schools, university campuses, a museum, a technology hub and potentially other industries such as concrete manufacturing (LLDC, 2015). Planning documents have articulated some general ambitions for promoting non-potable water supplies to support new housing and growth areas in London (e.g. The London Plan, Greater London Authority, 2015), and specifically in the Olympic Park planning area (e.g. Local Plan, LLDC, 2015). However, there is a lack of clear policy drivers for such schemes. In addition, regulations to govern activities such as sewer mining and NPR in the UK are yet to be comprehensively developed. 


\subsection{Data collection and analysis}

Qualitative data was purposively collected across the organisations involved with the case study to represent the diversity of stakeholders. The organisations represented by the data included national and regional (Greater London) government and regulatory organisations; Olympic Park management and planning organisations; the water company (Thames Water); and various non-potable water customers, end users and operation and maintenance contractors. Data consisted of semi-structured interviews ( $\mathrm{N}=30)$ and documents $(\mathrm{N}=36)$, which were collected to represent these four generalised stakeholder groups (Figure 2). Semi-structured interviews took place over a three year period (2012 to 2015). They lasted between 30 and 60 minutes and were recorded with permission before being transcribed. Interviews elicited views on: (i) the overall objectives for the project; (ii) hazards and risks involved with implementing and operating the NPR scheme; (iii) perceptions of water quality and quantity; (iv) the capabilities and the limitations of risk assessment and risk management activities; (v) the establishment of water quality criteria and a regulatory position; and (vi) organisational roles, responsibilities and interactions. Interviewees were given the opportunity to comment on the draft interview transcripts and thus confirm the authenticity of the data.

\section{Figure 2. Generalised stakeholder groups showing the distribution of collected data}

Documents included in the dataset were published between 2009 and 2015 and were used to supplement and triangulate the interview data. Collated documents included meeting minutes, conference presentations, commercial and public reports, policy statements and online web content (news articles and summary reports). The documents related to descriptions of the scheme and contained records of planning, design, scheme governance, risk management and regulatory discussions and decisions from the perspective of the different stakeholders involved. Figure 3 illustrates the timing of data collection relative to a selection of notable events in the scheme's 
development. The QSR NVivo 11 data management program was used to store interview transcripts and documents and to facilitate the qualitative analysis.

Figure 3. Time slice of selected project events and data collection

The study used semantic thematic analysis (Braun \& Clarke, 2006) to generate a structured view of the data that was predominantly inductive but also guided by concepts derived from literature. Themes and sub-themes were developed through iteration and using thematic network maps (Attride-Stirling, 2001) to aid the analytical process. Themes were continually reviewed and refined until they were considered to have largely distinctive meanings. Triangulation between sources of data (both interviews and documents) was used to explore patterns and firm up confidence in the collected views. Themes were thus the units of analysis that captured important aspects of the data and facilitated interpretive analysis to make sense of the data and describe what it meant with respect to the research questions (Braun and Clarke, 2006). Sub-themes gave structure and detail to the themes.

\section{Results}

The sections below present the four overall themes, and their associated sub-themes, which emerged from the analysis. The first three themes describe the main challenges that stakeholders perceived in relation to managing the risks associated with the implementation and operation of the NPR scheme. The final theme describes how the stakeholders thought that these challenges might best be tackled in order to improve scheme governance (Error! Reference source not found.). Example extracts from the data are provided in the tables as a means of illustrating the types of perspectives that contributed to the development of the themes and sub-themes. 


\begin{tabular}{|c|c|c|}
\hline Themes - Challenges & Sub-themes & Example extract to illustrate the challenge \\
\hline \multirow{3}{*}{$\begin{array}{l}\text { 1. The challenge is to } \\
\text { develop mutual } \\
\text { understandings of } \\
\text { diverse needs and } \\
\text { expectations }\end{array}$} & $\begin{array}{l}\text { 1.1. Understand water } \\
\text { quality requirements }\end{array}$ & $\begin{array}{l}\text { "So they didn't know because no one asked that question; how do you want your water? Out of the tap's fine. But when you } \\
\text { actually start analysing it and going oh, we don't want any whatever it is, we don't want this, we don't want that, it's just } \\
\text { ridiculous." (Int.PPM.05) }\end{array}$ \\
\hline & $\begin{array}{l}\text { 1.2. Understand risk } \\
\text { perceptions }\end{array}$ & $\begin{array}{l}\text { "We are disappointed to hear that this water will not be used to water the artificial hockey pitches due to perceived health } \\
\text { risks." (D.GRB.10) }\end{array}$ \\
\hline & 1.3. Maintain trust & $\begin{array}{l}\text { "Our commercial users are aware that they are using a different network, but they trust for it to be maintained in the same } \\
\text { way that the potable water network is." (Int.PPM.06) }\end{array}$ \\
\hline \multirow{3}{*}{$\begin{array}{l}\text { 2. To challenge is to } \\
\text { define clear roles and } \\
\text { responsibilities } \\
\text { (including on the } \\
\text { oversight of a range of } \\
\text { procedures, rules and } \\
\text { regulations) }\end{array}$} & $\begin{array}{l}\text { 2.1. Gain clear } \\
\text { commitment }\end{array}$ & $\begin{array}{l}\text { "No, I think that people - not in a bad way, people not really understanding what they're saying and what they're committed } \\
\text { to." (Int.PPM.05) }\end{array}$ \\
\hline & 2.2. Link procedures & $\begin{array}{l}\text { "Links are not always clear between the reclaimed water safety plan spreadsheet and associated procedures and there is an } \\
\text { opportunity to enhance inter-connectedness of elements associated with the safety plan." (Int.WC.01) }\end{array}$ \\
\hline & $\begin{array}{l}\text { 2.3. Streamline rules and } \\
\text { regulations }\end{array}$ & $\begin{array}{l}\text { "In the UK, dual reticulation schemes of this type are rare and the guidance available is not very specific. The current UK } \\
\text { guidance on a whole range of related topics, such as pipework labelling, could benefit from being streamlined and } \\
\text { consolidated. (D.WC.54) }\end{array}$ \\
\hline \multirow{4}{*}{$\begin{array}{l}\text { 3. The challenge is to } \\
\text { improve awareness, } \\
\text { knowledge and } \\
\text { capabilities } \\
\text { (particularly industry } \\
\text { experience and } \\
\text { decision making) }\end{array}$} & 3.1 Improve awareness & $\begin{array}{l}\text { "I don't think many people know about it. Just do a survey on people exiting the park when they leave were they even } \\
\text { aware?" (Int.CEUC.05) }\end{array}$ \\
\hline & $\begin{array}{l}\text { 3.2. Improve technical } \\
\text { knowledge and } \\
\text { understanding }\end{array}$ & $\begin{array}{l}\text { "There needs to be a better understanding of what happens with loss of treatment integrity, particularly with the membrane } \\
\text { which provides an important barrier". (Int.WC.03) }\end{array}$ \\
\hline & $\begin{array}{l}\text { 3.3. Improve industry } \\
\text { skills and experience }\end{array}$ & $\begin{array}{l}\text { "There were some issues with the non-potable system at the start of the project, including incorrect specifications" } \\
\text { (Int.WC.04) }\end{array}$ \\
\hline & $\begin{array}{l}\text { 3.4. Improve decision- } \\
\text { making }\end{array}$ & $\begin{array}{l}\text { "During the initial operational period, the uncertainty over what demands were actually going to materialise was not helpful } \\
\text { but were inevitable due to the nature of the project." (D.WC.43) }\end{array}$ \\
\hline Themes - Solutions & Sub-themes & Example extract to illustrate the solution \\
\hline \multirow{2}{*}{$\begin{array}{l}\text { 4. The solution is to use } \\
\text { inclusive, collaborative } \\
\text { and learning processes } \\
\text { to build knowledge and } \\
\text { mutual understandings }\end{array}$} & $\begin{array}{l}4.1 \text { informally generate } \\
\text { knowledge through risk } \\
\text { taking, experimentation } \\
\text { and learning by doing }\end{array}$ & $\begin{array}{l}\text { "Sometimes you have to take risks initially to gain knowledge and once you've got that knowledge then you can manage } \\
\text { those risks."(Int.WC.14)† }\end{array}$ \\
\hline & $\begin{array}{l}\text { 4.2 Formally use different } \\
\text { types and levels of } \\
\text { engagement to } \\
\text { encourage learning }\end{array}$ & $\begin{array}{l}\text { "I think a bit more training on it would be handy, without a doubt. Just to flag it up to people that have been on the park as } \\
\text { long as I have or whatever... Refresh every year or something like that." (Int.CEUC.03) }\end{array}$ \\
\hline
\end{tabular}

200 TData reference system: Int = Interviewee. D=Document. 01 = Interviewee/Document identification number for group. Stakeholder group codes: CEUC = Customers, End Users and 201 Contractors; WC = Water Company, PPM = Park Planning and Management, GRB = Governmental and Regulatory Bodies. 


\subsection{The challenge of developing mutual understandings of diverse expectations}

203

204

205

206

207

208

209

210

211

212

The challenge perceived by the stakeholder groups of developing mutual understandings of needs and expectations was a dominant theme. Expectations were identified as differing particularly over aspects of non-potable water quality and the associated perceptions of risks relating to the possibility of certain contaminants in the water. Also, closely related to both of these sub-themes, maintaining trust was identified across the stakeholder groups as an important challenge to confront when attempting to develop mutual understandings.

The first sub-theme related to understanding the non-potable water quality needs of the customers and end users and also the expectations of the other stakeholder groups. The non-potable water was originally conceived to be used for toilet flushing, parkland irrigation, cooling tower water (energy centre) and hockey field irrigation, and, as such, there were a number of differences over which quality characteristics were considered important. Microbial parameters were clearly of interest (given the imperative of protecting public health), however, water quality preferences also related to technology risks (i.e. the water's potential impact on irrigation equipment or cooling tower operations) and aesthetic characteristics (e.g. colour and odour). On reflection, a number of interviewees from the customer, park management and water company stakeholder groups thought that the quality standards were stricter than they necessarily needed to be and there was some indication of a desire for some quality parameters to be adjusted. However, it was unclear how such an adjustment could be accomplished. On the other hand, it was thought that changing the water quality might deter new customers from connecting in the future and thus the water company was reluctant to do this.

The challenge of understanding the risk perceptions of different stakeholders constituted the second sub-theme. Different views on risk were identified in the data - for example, regulators, the water 
company and park management were concerned about the risks to irrigation workers from their exposure to the non-potable water, but the workers themselves indicated they had few concerns. An example of these different perspectives related to the extent of personal protection equipment needed for irrigation contractors, with workers perceiving some occupational health and safety requirements as overly conservative. Furthermore, perceptions of significant risks were seen as underpinning the failure to connect both the hockey fields and the energy centre cooling towers to the non-potable water network. For the energy centre, that data suggests a failure by the water company and the park management to fully comprehend the risk management expectations of the centre's operators. Whilst health and safety (legionella risks) and operational risks were suggested as unresolved issues, the data also suggested complications to contractual arrangements as well. On the other hand, the decision not to irrigate the hockey fields (with non-potable water) was attributed to health risk concerns of the Olympic organisers (who at the time were also the customers). For the water company interviewees, there were some health risk concerns with irrigating hockey fields as well. However, on reflection, it was largely agreed that the failure to connect these two uses had introduced cost risks for the scheme that impacted on its longer-term viability.

The last sub-theme encompassed the challenge of maintaining trust between the stakeholder groups. The analysis found a nervousness, particularly from the water company and regulators, around the potential for misuse or unintended use of the non-potable water supply, resulting in negative health consequences (thus increasing perceptions of risk). In other words, the water company and regulators showed a slight degree of mistrust in the end users of the non-potable water, and/or those who might come into contact with the distribution network. Conversely, other stakeholders' trust in the water company to consistently supply safe water was repeatedly described by interviewees. This was supported by the view that the water company is a responsible 

water regulation were considered by some to contradict the promotion of non-potable water use.

organisation and would not compromise on public health. In summary, whilst levels of trust described by all stakeholder groups were interpreted as being sufficient, the analysis also identified that adverse events - e.g. the (potentially unintended) misuse of the non-potable supply - could significantly impact on this.

\subsection{The challenge of clarifying roles and responsibilities}

Analysis of the interview and document data illuminated the challenge of clarifying roles and responsibilities for individuals, within organisations and between organisations. This theme further encapsulated the challenge of unifying the various procedures, rules and regulations that were overseen by the different organisations. The results showed that the apparent duplication of responsibilities and/or poor definition of responsibilities had the potential to increase risk.

The first sub-theme described the challenge of gaining commitment from stakeholders to support and implement the scheme. The implication was that a lack of commitment intensified the challenge of clarifying roles and responsibilities and potentially led to fragmented decisions. The Olympics and Paralympic games were described as an important catalyst for gaining initial commitment to the scheme, but many felt that commitment has waned after the games. Moreover, the short-term nature of the OFWRP's contract (2012-2019) was described as introducing uncertainty and hindering commitment from potential new non-potable water customers - and thus impacting on the longerterm viability of the scheme. On the other hand, contractual arrangements were seen as helpful in that they established clear commitment to certain responsibilities, such as water quality compliance reporting. Finally, some interviewees highlighted a lack of commitment from regulators, outside of those closely involved with the scheme. For example, occupational health and safety and drinking 
In a similar vein, the challenge of improving links between a range of managerial procedures, as well as consolidating these where there was duplication, was the second sub-theme. The data described examples of overlapping requirements, such as the Water Reuse Safety Plan approach overlapping unnecessarily with aspects of health and safety assessment. Other interviewees, however, identified strengths derived from unifying existing procedures, such as transferring the catchment to tap risk assessment format from drinking water to reuse. Notably, there was some confusion highlighted as to who was responsible for overseeing certain procedures (e.g. for undertaking certain risk management activities such as installing signage). This particularly related to demarcating areas inside and outside of buildings thus introducing zones where responsibilities for managing risks were not clear.

The final sub-theme described challenges arising from fragmented or overlapping rules and regulations. For example, whilst the use of the United States Environmental Protection Agency nonpotable water quality standards was described by some as beneficial, there were also problems attributed to interpreting conflicts with UK standards and regulation (including drinking water quality regulation). The lack of UK guidance and standards for non-potable water quality and distribution network construction was often described as a significant challenge for scheme governance. For the guidance that did exist, there was confusion expressed around some conflicting recommendations and terminology. For example, British standards for rainwater harvesting differ from those for greywater recycling on some water quality parameters, even though the two technologies are often combined. The multiple layers of overlapping planning responsibilities for London was also thought to introduce confusion. For example, planning requirements for nonpotable water supplies in new developments differed in the guidance produced at national, regional and local levels. Finally, whilst the bespoke regulatory position developed for the site was described as enabling the scheme to progress (in a previously unregulated area), it was also suggested that 
future schemes in London (or other cities) would not necessarily benefit from this as the activity remained unregulated.

\subsection{The challenge of improving awareness, knowledge and capabilities}

All stakeholder groups highlighted the challenge of improving awareness, knowledge and capabilities around the risks associated with NPR. Whilst the four stakeholder groups differed in some respects on the types of risks they were concerned about, there was also concordance. Common points of focus included public health risks and particularly the potential for cross-connections with the drinking water supply being introduced through, for example, a lack of awareness of the scheme. The analysis found that, while many stakeholders felt that aspects of awareness, technical knowledge and capabilities had improved over time, new dimensions to these challenges had also been introduced.

The challenge of improving awareness of the scheme and its associated risks (e.g. awareness of the health risks associated with using non-potable water) was a sub-theme. Perceptions of a lack of awareness focused on the contractors responsible for constructing the non-potable water distribution network, both initially and with new network extensions. Additionally, interviewees highlighted that the number of contractors working on the Park for different landscape and construction projects exacerbated the need for raising awareness. The lack of general awareness was thought to arise principally from the scheme being the first of its kind in the UK. There was some evidence of an increased awareness of the scheme occurring through some contractors being on the site over a number of years. Other broader concerns related to public awareness of the water resource issues in London, awareness of NPR as a potential solution for those issues, and awareness of the NPR scheme at the Olympic Park. 
327 The next related sub-theme described the challenge of improving technical knowledge and understanding of various aspects of the scheme, including scheme planning, design, installation and operation. Once again, much of this related to the scheme being the first of its kind in the UK. The stakeholder groups described a range of aspects to this sub-theme and focused on: compliance with water regulations, public health, environmental impacts and the cost-benefit balance. For example, there were concerns that the scheme might not be cost effective, but knowledge to support such an assessment was limited. It was clear that many stakeholders thought knowledge and understanding had increased over time. However, whilst technical knowledge of the scheme was thought to have improved in many areas, it was also suggested that this was unevenly distributed across stakeholders. For example, there were concerns that changes in key staff meant that valuable knowledge could be easily lost. The data also highlighted a desire to improve knowledge and understanding of the contribution NPR could make to water resource management in London, as a means of encouraging similar schemes across the city.

The challenge of improving capabilities (skills and experience) within the industry - particularly related to specification, procurement and construction - was another sub-theme. This sub-theme is closely associated with those above, but it specifically highlights the role of industry experience. Many of the challenges highlighted in the data related to the installation of the pipework for the non-potable distribution system and a lack of compliance with regulations, which were attributed to a lack of skill and experience in the industry. The main concerns raised were thus water regulation compliance (e.g. pipe fittings) and the risk of cross-contamination both inside buildings and in network. 
Finally, the challenge of making decisions under uncertain conditions was highlighted in the data.

This data summarised perspectives relating to early design decisions that had (unintentionally) introduced other scheme risks. Such introduced risks included the nature of the non-potable distribution network design (being dendritic rather than a ring main, which creates the potential for stagnation), inaccuracies in the original demand estimates (leading to some operational and costbenefit risks), and design specifications for some equipment associated with water treatment (leading to higher than necessary energy and chemical use). Notably, the colourless nature of the non-potable water (which was a specific treatment requirement early on) was considered by one interviewee as potentially introducing risks as it was visually indistinguishable from the drinking water supply (making cross-contamination difficult to detect).

\subsection{Solutions to these challenges - collaboration and learning}

A single theme summarised how the stakeholders perceived that inclusive opportunities for collaboration and learning were necessary parts of processes to improve scheme governance. Joint working towards common goals was repeatedly raised as a preferred practice, as illustrated by the following interviewee: "Different projects require different inputs by different organisations and working together in a collaborative way. We've worked all the way through like that. Something that's really helped facilitate that understanding [of needs and expectations] and relationship building from our perspective is that we've always had individuals co-located with the contractors... with the design engineers and contractors, the delivery bodies" (Int.GRB.05: Governmental and Regulatory stakeholder group). The theme was also supported by data that highlighted where a lack of inclusion, collaboration or learning had meant that some challenges had not been addressed. For example, some data described frustrating attempts to arrange meetings intended to discuss water quality criteria and scheme design, concluding that some "meetings were generally not well attended and little was learnt" (D.WC.43: Water Company stakeholder group). Many of the specific 
examples of collaboration in practice focused on risk management (using a Water Reuse Safety Plan approach) and the negotiation of water quality standards and the regulatory position for the scheme.

380

The first sub-theme identified a number of more informal processes that supported inclusiveness, collaborative working and learning. Knowledge generation, particularly in co-working situations, was described as important for improving capabilities in risk management activities and operational and design decision making. Informal discussions often took place during scheduled risk management activities, particularly between the water company and customers, end users, contractors and members of the public. For example, such discussions were described as occurring during testing for cross-connections, flushing of the non-potable water network, water quality sampling and water regulation inspections. One interviewee discussed an informal communication network that irrigation workers had established to negotiate non-potable water network risks (e.g. loss of pressures and lack of supply) during periods of high demand for non-potable water. The data highlighted a link between creating the right environment for risk taking and achieving desirable outcomes - described by one interviewee as the need to learn through taking risks in order to generate important knowledge to improve risk management. This conceptual thread extended to the role of experimentation for generating learning opportunities and new knowledge. When discussing the management of water quality risks during winter, one interviewee suggested an untried solution and that it was worth "probably just taking a risk and see what happens" (Int.CEUC.05: Customer and End User stakeholder group).

The scheme itself was seen as a beneficial experiment for generating knowledge, and for engaging a range of stakeholder (including the general public), in order to pave the way for similar schemes elsewhere in London. Being involved with the scheme was considered as a learning opportunity that 
was described by one interviewee as improving knowledge and capabilities, "because I had to immerse myself in it and understand it, I'm very comfortable talking about it, telling people how they can use it. But across the industry, that's not the case." (Int.PPM.05: Park Planning and Management stakeholder group). Finally, it was recognised that the innovative nature of this scheme meant that some mistakes were inevitable (as with any innovative technology), but these could provide many opportunities for leaning-by-doing, as one interviewee described: "Because we've actually picked up loads of little things that you do when you're going round and checking everything; if you make a mistake, then basically this happens" (R.WC.14: Water Company stakeholder group).

The second sub-theme summarised formal processes for knowledge sharing and learning, including training, educational briefings, site tours and information sharing (communication). Whilst many engagement activities often had specific agendas, it was felt that some also allowed for broader discussions of scheme governance, water resource management and risk. It was suggested that educational briefings and site tours encouraged those involved to ask questions and raise discussions which contributed to improving their awareness (particularly as many individuals were only involved with certain aspects of the scheme). Furthermore, examples in the data described the site tours as a platform to engage customers and stakeholders in debate on London's water resource management. It was suggested that engagement framed around the Water Reuse Safety Plan has led to the relaxation of a number of water quality monitoring requirements, thus indicating how formal knowledge transfer had helped develop mutual understandings of acceptable water quality risks. There were a number of useful learnings on engagement documented for the scheme, on interviewee described how early discussions and negotiations helped develop a service level agreement to clarify organisational responsibilities. Another interviewee described their efforts in talking about the scheme with the different venues as helping to understand different risks and also raise awareness. 
428 Although different types and levels of engagement were seen as necessary for sharing knowledge,

429 learning and relationship building, a number of constraints were also described. Some felt

430 improvements could be made in the exchange of information (a communication deficit). For

431 example, one interviewee described how a lack of suitably timed communication meant that some contractors were not initially aware of design and installation standards. Other examples included requests for more communication of operational incidents (e.g. an expected change in water pressure) and more education on risks and precautions to improve awareness, particularly for end users. Another interviewee thought a lack of involvement from a number of different departments in the water company had led to fragmentation in scheme decisions and its ongoing management and that more focus on early engagement might have helped. The analysis flagged a number of obstacles to engagement, including the time required, problems with organisation structures, the number and variety of organisations involved and demands being put on individuals. One interviewee from the customer group identified how they were sometimes not included in stakeholder meetings and therefore didn't have direct access to information they wanted. Another interviewee summarised some difficulties carrying out successful engagement, "it's a big investment, you need to have a knowledgeable technical type person that can do customer engagement" often desired as a means of facing governance challenges, this was not always matched in practice.

\section{Discussion}

\section{$447 \quad 4.1$ Collaboration and learning to address governance challenges}

448 The results highlighted how stakeholders perceive collaboration and joint working processes as 449 helpful to promote learning and to forge mutual understandings, and thereby contribute to more effective scheme governance. This study thus provides some empirical support to previous findings 
advocating collaborative approaches to meet diverse challenges for the governance of water quality

452 (Dunn et al., 2015) and scheme risks (Perrier et al., 2014). This finding also leads to consideration of broader collaborative (or social) learning theory, which suggests less hierarchical modes of water governance (Pahl-Wostl et al., 2008a). Whilst this is relevant for alternative water systems like community-scale NPR, the potential for adverse events (like technical failures) to have a detrimental effect on collaborative learning processes should also be recognised (Domènech and Saurí, 2010). Furthermore, evidence from this study also shows that although collaborative processes were desired, this was not necessarily matched in practice. This mismatch supports previous findings in water governance, for example where guidelines may contain aspirations for collaborative processes that are not implemented (Dore et al., 2012). So whilst it is recognised that collaboration and learning can help to clarify misunderstandings, there will be procedural and behavioural challenges to this - even when stakeholders are willing.

This study highlighted some practical hurdles in resolving stakeholder differences, including the time necessary for negotiations or difficulties communicating with individuals or organisations. With respect to addressing these and other scheme governance challenges, this study found evidence of the benefits of stakeholder deliberation during practice-based activities and particularly those associated with risk management. A notable finding was that informal collaboration occurred during practical risk management tasks. It was thought that these informal working relationships helped to promote learning and to mitigate risks. This finding firstly supports previous studies that suggested collaborative learning occurs when stakeholders engage in common tasks based on inter-dependent 472 relationships (Moglia et al., 2011). Furthermore, this finding supports the relevance of informal 473 communications in environmental risk governance (Mauelshagen et al., 2014) and particular when 474 stakeholders might not see good reason for formal engagement (Bos et al., 2013). What this 475 contribution specifically adds is that there can be benefits to informal collaboration during risk 
management activities for non-potable water reuse. Such opportunities are likely to arise around non-potable network management where the different stakeholder groups most frequently meet. This finding has implications for the content of risk-based management frameworks currently promoted for water reuse. In particular, future guidance might focus attention on recommendations for approaching informal engagement and for establishing inclusive risk management teams (that include a range of stakeholders and representatives from the communities of practice) - previously suggested for NPR (Attwater and Derry, 2005).

Findings of this study provide support for the use of a range of different types of engagement tailored to the needs of different stakeholders as well as to their available resources (OECD, 2015). Whilst it is not surprising that formally planned engagement activities may need to change over time in response to stakeholders needs (Turner et al., 2016), this study also suggests that a level of experimentation is necessary to discover which techniques work best. The results from this study also corroborate previous findings around the benefits of using information exchange to support collaboration instead of only seeking to provide expert advice (Pahl-Wostl et al., 2008b). However, whilst this study supports the idea that involving more stakeholders in collaborative processes may help legitimise risk-based decisions (Hermans et al., 2012), previous studies have highlighted numerous difficulties in conceiving and implementing formal collaborative initiatives. For instance, such arrangements may be weakened by vague definitions of roles and responsibilities (Hahn, 2011), which is of particular relevance to NPR schemes as the importance of defining roles and responsibilities has been identified as critical to their success (Farrelly and Brown, 2011). Thus, illconceived formal collaborative processes could potentially exacerbate the fragmentation of different procedures and rules (Hanjra et al., 2012) and increase the potential for conflict (Turner et al., 2016). Moreover, these processes will also face challenges from time constraints, intraorganisational fragmentation and unrealistic demands put on individuals. This contribution has 
highlighted the benefits of incorporating more informal collaborative opportunities that can help address some of these issues and bolster formal collaboration efforts.

503

\subsection{Implications for future NPR schemes in megacities}

The findings of this study suggest there are benefits to understanding case-specific experiences to develop practical knowledge on how to negotiate a range of critical risks for NPR scheme implementation and operation. For stakeholder inclusion in future NPR scheme governance, this case study has highlighted that both formal and informal engagement mechanisms should be applied, as they are suited to different stakeholder groups. The findings support the view that formalised engagement activities such as site tours (Marks, 2006) or community forums (Russell et al., 2008) can provide a platform for raising questions and discussing concerns. Secondly, more informal collaboration can be stimulated by specific actions (Domènech and Saurí, 2010) and this study puts forward the benefit of focusing on inclusive opportunities in day to day risk management activities. Time poor contractors and local managers may prefer more informal, activity based collaboration. On the other hand, the Water Reuse Safety Plan format provides a formal vehicle for discussing risks with regulators or water resource managers. Many world regions have made considerable progress in developing risk management and scheme governance guidance for NPR (e.g. NRMMC EPHC \& AHMC, 2006; USEPA, 2012), but these tend to focus predominantly on formal mechanisms for stakeholder engagement and the management of public heath and environmental risks. There are two implications: (i) a broader suite of informal, practice-based opportunities for collaboration could suit a wider range of stakeholders and help improve future schemes, and (ii) existing risk management guidance would benefit from incorporating the management of other critical scheme risks, particuarly those of a financial and a regulatory nature. 
525 Technological solutions like NPR could address emerging water supply challenges in megacities

526 (Tjandraatmadja et al., 2005) and help diversify their water supply infrastructure in order to build

527 resilience (Marlow et al., 2013). As previously mentioned, the number and diversity of stakeholders

528 in megacities can lead to fragmentation, or a lack of integration, of urban water management

529 solutions (Li et al., 2015) and of stakeholder responsibilities (Varis et al., 2006). However, megacities

530 can also provide fertile ground for local-scale experimentation with new solutions, because they

531 provide opportunities to include 'outsiders' or fringe stakeholders in engagement processes, thus

532 diffusing knowledge and experiences more broadly and across a range of governance scales, from

533 local to national (Farrelly and Brown, 2011). This can allow a broader range of perspectives to

534 infiltrate the engagement processes, and can also help local solutions to be 'scaled up' more quickly.

535 The case study presented here has illustrated how a localised NPR scheme can present a focal point

536 for such experimentation in a megacity context. Stakeholders demonstrated a willingness to 'learn

537 by doing' and experiment, not just with technology, but with different risk managements

538 approaches and different mechanisms for collaboration. Lessons from these activities could

539 potentially be scaled up as urban intensification increases, and particularly as NPR becomes seen as

540 a more viable solution for cities like London and the wider region (e.g. European Commission, 2016).

541

\section{Conclusion}

543 Using data from semi-structured interviews and documents, this study identified three main

544 challenges associated with the governance of an NPR scheme in London: 1) the need to develop

545 mutual understandings of diverse expectations; 2 ) the need to clarify roles and responsibilities; and

546 3) the need to improve awareness, knowledge and capabilities. Findings also showed that

547 collaboration and learning processes, especially those focused on risk and risk management

548 activities, can help address these challenges. In particular, our findings highlighted that risk 
management activities around the non-potable water network provided opportunities for more informal modes of collaboration. Furthermore, this study has shown that a broader spectrum of engagement approaches (both formal and informal) can facilitate dialogue around divergent objectives and help build relationships and maintain trust. Such collaborative processes can help make governance mechanisms more responsive to the risk and stakeholder dynamics characteristic of megacities like London. These case specific findings can inform practices for future NPR schemes in megacities.

Non-potable reuse is a viable tool to help address the water resource challenges of megacities. In turn, megacities provide challenging but fruitful contexts in which to develop more effective governance approaches for NPR schemes, in part by facilitating experimentation with, and scale-up of niche solutions. The synthesis of learnings and experiences from similar case studies will help to build better understandings of common solutions to governance challenges for NPR schemes. However, more evidence is needed to illustrate how NPR can contribute to more integrated water resource management approaches, as well as related public health, environmental and economic challenges for megacities Future research could also explore the relationship between stakeholder intentions and actual behaviours, for example, where knowledge sharing is envisioned but not necessarily practised. This may be extended to examine stakeholders' willingness to actively participate in NPR risk management, such as through catchment management or behaviour based risk barriers. Finally, there are opportunities to evaluate practice-based mechanisms for collaboration and deliberation, which can help to legitimise urban water management proposals.

570 Collating this evidence can contribute to improving the integration of water management solutions 571 for growing urban agglomerations like London and other megacities. 


\section{Acknowledgements}

574 The views expressed here are those of the authors and do not necessarily represent the individuals or organisations involved in the research. However, the authors are grateful to all those who gave up their time to participate in this study, and we offer thanks to them and the organisations they represent. The authors would also like to acknowledge Nikki Dudley for her help with transcribing interviews. This research was co-funded by the UK's Engineering and Physical Science Research

\section{References}

Attride-Stirling, J., 2001. Thematic Networks: an analytic tool for qualitative research. Qual. Res. 1, 385-405.

Attwater, R., Derry, C., 2005. Engaging communities of practice for risk communication in the Hawkesbury Water Recycling Scheme. Action Res. 3, 193-209. doi:10.1177/1476750305052144

Bieker, S., Cornel, P., Wagner, M., 2010. Semicentralised supply and treatment systems: Integrated infrastructure solutions for fast growing urban areas. Water Sci. Technol. 61, 2905-2913. doi:10.2166/wst.2010.189

Bos, J.J., Brown, R.R., Farrelly, M.A., 2013. A design framework for creating social learning situations. Glob. Environ. Chang. 23, 398-412. doi:10.1016/j.gloenvcha.2012.12.003 doi:10.1191/1478088706qp063oa 
Campbell, A.C., Scott, C. a., 2011. Water reuse: policy implications of a decade of residential reclaimed water use in Tucson, Arizona. Water Int. 36, 908-923. doi:10.1080/02508060.2011.621588

Dillon, P., Toze, S., Page, D., Vanderzalm, J., Bekele, E., Sidhu, J., Page, D., Vanderzalm, J., 2010. Managed aquifer recharge: rediscovering nature as a leading edge technology. Water Sci. Technol. 62, 2338-2345. doi:10.2166/wst.2010.444

Domènech, L., Saurí, D., 2010. Socio-technical transitions in water scarcity contexts: Public acceptance of greywater reuse technologies in the Metropolitan Area of Barcelona. Resour. Conserv. Recycl. 55, 53-62. doi:10.1016/j.resconrec.2010.07.001

Dore, J., Lebel, L., Molle, F., 2012. A framework for analysing transboundary water governance complexes, illustrated in the Mekong Region. J. Hydrol. 466-467, 23-36. doi:10.1016/j.jhydrol.2012.07.023

Dunn, G., Harris, L., Bakker, K., 2015. Microbial risk governance: challenges and opportunities in fresh water management in Canada. Can. Water Resour. J. 40, 237-249. doi:10.1080/07011784.2015.1043648

European Commission, 2016. Guidelines on Integrating Water Reuse into Water Planning and Management in the context of the WFD. European Commission, Brussels.

Farrelly, M., Brown, R., 2011. Rethinking urban water management: Experimentation as a way forward? Glob. Environ. Chang. 21, 721-732. doi:10.1016/j.gloenvcha.2011.01.007

Ferguson, B.C., Brown, R.R., Frantzeskaki, N., de Haan, F.J., Deletic, A., 2013. The enabling institutional context for integrated water management: lessons from Melbourne. Water Res. 47, 7300-14. doi:10.1016/j.watres.2013.09.045

Furlong, C., De Silva, S., Gan, K., Guthrie, L., Considine, R., 2017. Risk management, financial evaluation and funding for wastewater and stormwater reuse projects. J. Environ. Manage. 
621 Furlong, C., Gan, K., De Silva, S., 2016. Governance of Integrated Urban Water Management in Melbourne, Australia. Util. Policy 2002, 1-11. doi:http://dx.doi.org/10.1016/j.jup.2016.04.008

Goodwin, D., Raffin, M., Jeffrey, P., Smith, H.M., 2015. Applying the water safety plan to water reuse: towards a conceptual risk management framework. Environ. Sci. Water Res. Technol. doi:10.1039/C5EW00070J

Greater London Authority, 2015a. City in the East. Greater London Authority, London.

Greater London Authority, 2015b. GLA 2014 round of trend-based population projections - Results. Update 03-2015. Greater London Authority, London.

Greater London Authority, 2015c. The London Plan. Greater London Authority, London.

Hahn, T., 2011. Self-Organized Governance Networks for Ecosystem Management : Who Is Accountable? Ecol. Soc. 16, 18.

Hanjra, M.A., Blackwell, J., Carr, G., Zhang, F., Jackson, T.M., 2012. Wastewater irrigation: Implications for water governance and public policy. Int. J. Hyg. Environ. Health 215, 255-269. doi:10.1016/j.ijheh.2011.10.003

Hermans, M.A., Fox, T., van Asselt, M., 2012. Risk Governance, in: Roeser, S., Hillerbrand, R., Sandin, P., Peterson, M. (Eds.), Handbook of Risk Theory. Springer Science, Berlin, pp. 1094-1112.

Hills, S., James, C., 2015. The Queen Elizabeth Olympic Park Water Recycling System, London, in: Memon, F.A., Ward, S. (Eds.), Alternative Water Supply Systems. IWA Publishing, London, pp.

Hochstrat, R., Wintgens, T., Melin, T., 2008. Development of integrated water reuse strategies. 
643

Huxedurp, L.M., Pálsdóttir, G.P., Altavilla, N., 2014. Risk-based planning for water recycling in an Australian context. Water Sci. Technol. Water Supply 14, 971. doi:10.2166/ws.2014.058

IRGC, 2010. Emerging risks in Megacities. International Risk Governance Council, Geneva, Switzerland.

Kimura, K., Funamizu, N., Oi, Y., 2013. On-site water reclamation and reuse in individual buildings in Japan, in: Lazarova, V., Asano, T., Bahri, A., Anderson, J. (Eds.), Milestones in Water Reuse. IWA Publishing, London, pp. 169-174.

Knight, H., Maybank, R., Hannan, P., King, D., Rigley, R., 2012. Lessons learned from the London 2012 Games Construction Project - The Old Ford Water Recycling Plant and Non-Potable Water Distribution Network. Olympic Delivery Authority. London.

Lebel, L., Sinh, B.T., Nikitina, E., 2015. Adaptive governance of risks: climate, water and disasters, in: Shaw, R., Pulhin, J.M., Pereira, J.J. (Eds.), Climate Change Adaptation and Disaster Risk Reduction : Issues and Challenges. Emerald Group Publishing Limited, Bingley, pp. 115-142.

Li, E., Endter-Wada, J., Li, S., 2015. Characterizing and Contextualizing the Water Challenges of Megacities. J. Am. Water Resour. Assoc. 51, 589-613. doi:10.1111/1752-1688.12310

LLDC, 2015. Local Plan 2015 to 2031. London.

Marks, J., 2006. Taking the Public Seriously: The Case of Potable and Non Potable Reuse. Desalination 187, 137-147. doi:10.1016/j.desal.2005.04.074

Marks, J., Zadoroznyj, M., 2005. Managing Sustainable Urban Water Reuse: Structural Context and Cultures of Trust. Soc. Nat. Resour. An Int. J. 18, 37-41. doi:10.1080/08941920590947995

Marlow, D.R., Moglia, M., Cook, S., Beale, D.J., 2013. Towards sustainable urban water management: A critical reassessment. Water Res. 47, 7150-7161. doi:10.1016/j.watres.2013.07.046

Mauelshagen, C., Smith, M., Schiller, F., Denyer, D., Rocks, S., Pollard, S., 2014. Effective risk 
666

667

668

669

670

671

672

673

674

675

676

677

678

679

680

681

682

683

684

685

686

687

688

689

governance for environmental policy making: A knowledge management perspective. Environ.

Sci. Policy 41, 23-32. doi:10.1016/j.envsci.2014.04.014

Moglia, M., Alexander, K.S., Sharma, A., 2011. Discussion of the enabling environments for decentralised water systems. Water Sci. Technol. 63, 2331-2340. doi:10.2166/wst.2011.443

NRMMC EPHC \& AHMC, 2006. Australian Guidelines for Water Recycling: Managing Health and Environmental Risks (Phase 1). Natural Resource Ministerial Management Council, Environment Protection and Heritage Council and Australian Health Ministers, Canberra.

OECD, 2015. Stakeholder Engagement for Inclusive Water Governance, OECD Studies on Water. OECD Publishing. Paris. doi:10.1787/9789264231122-en

Pahl-Wostl, C., Mostert, E., Tàbara, D., 2008a. The Growing Importance of Social Learning in Water Resources Management and Sustainability Science. Ecol. Econ. 13, 24.

Pahl-Wostl, C., Tàbara, D., Bouwen, R., Craps, M., Dewulf, A., Mostert, E., Ridder, D., Taillieu, T., 2008b. The importance of social learning and culture for sustainable water management. Ecol. Econ. 64, 484-495. doi:10.1016/j.ecolecon.2007.08.007

Perrier, E., Kot, M., Castleden, H., Gagnon, G.A., 2014. Drinking water safety plans : barriers and bridges for small systems in Alberta , Canada. Water Policy 16, 1140-1154. doi:10.2166/wp.2014.207

Russell, S., Lux, C., Hampton, G., 2008. Beyond "Information": Integrating Consultation and Education for Water Recycling Initiatives. Soc. Nat. Resour. 22, 56-65. doi:10.1080/08941920801910666

Sosa-Rodriguez, F.S., 2011. Exploring the risks of ineffective water supply and sewage disposal: A case study of Mexico City. Environ. Hazards 9, 135-146. doi:10.3763/ehaz.2010.0016

Thames Water, 2014. Revised Draft Water Resources Management Plan (2015-2040) - Section 6: Baseline Supply Demand Position. Reading, UK. 
690

691

692

693

694

695

696

697

698

699

700

701

702

703

704

705

706

707

708

709

710

711

Tjandraatmadja, G., Burn, S., Mclaughlin, M., Biswas, T., 2005. Rethinking urban water systems revisiting concepts in urban wastewater collection and treatment to ensure infrastructure sustainability. Water Sci. Technol. Water Supply 5, 145-154.

Toze, S., 2006. Water reuse and health risks - real vs. perceived. Desalination 187, 41-51. doi:10.1016/j.desal.2005.04.066

Turner, A., Mukheibir, P., Mitchell, C., Chong, J., Retamal, M., Murta, J., Carrard, N., Delaney, C., 2016. Recycled water - Lessons from Australia on dealing with risk and uncertainty. Water Pract. Technol. 11, 127-138. doi:10.2166/wpt.2016.015

United Nations, 2015. World Urbanisation Prospects: 2014 Revision. United Nations, Department of Economic and Social Affairs, Populatin Division, New York.

USEPA, 2012. Guidelines for Water Reuse. United States Environmental Protection Agency, U.S. Agency for International Development. Washington, D.C.

Van Leeuwen, K., Sjerps, R., 2015. Istanbul: the challenges of integrated water resources management in Europa's megacity. Environ. Dev. Sustain. doi:10.1007/s10668-015-9636-z

Varis, O., Biswas, A.K., Tortajada, C., Lundqvist, J., 2006. Megacities and Water Management. Int. J. Water Resour. Dev. 22, 377-394. doi:10.1080/07900620600684550

West, C., Kenway, S., Hassall, M., Yuan, Z., 2016. Why do residential recycled water schemes fail? A comprehensive review of risk factors and impact on objectives. Water Res. 102, 271-281. doi:10.1016/j.watres.2016.06.044

Yin, R.K., 2011. Applications of Case Study Research: Third Edition. SAGE Publications Ltd. 